\title{
A proposta de produção escrita de gêneros literários nos livros didáticos: a estabilidade diante da dinamicidade da linguagem
}

DOl: http://dx.doi.org/10.21165/el.v50i3.2892

\section{Marina Totina de Almeida Lara'}

\section{Resumo}

Considerando a importância das práticas de linguagem em diferentes materialidades linguísticas na escola e as indicações das políticas públicas nacionais para que isso ocorra, este artigo tem como objetivo discutir as propostas de produção escrita de gêneros literários em materiais didáticos. Para tanto, partindo dos documentos oficiais nacionais, que norteiam as práticas de ensino/aprendizagem brasileiras, o artigo apresenta reflexão sobre estudos discursivos acerca do trabalho com gêneros do discurso no campo escolar. Por fim, apresenta uma análise da presença do gênero do discurso conto em um livro que circula na rede particular de ensino, destinado ao $1^{\circ}$ ano, em atividades de produção de textos. A perspectiva teórico-metodológica é a dos estudos bakhtinianos do discurso, da qual destacamos os conceitos de enunciado concreto, gêneros do discurso e campo de atividade.

Palavras-chave: produção de textos; gêneros do discurso; estudos bakhtinianos.

1 Universidade Estadual Paulista "Júlio de Mesquita Filho" (UNESP), Araraquara, São Paulo, Brasil; m.almeidalara@hotmail.com; https://orcid.org/0000-0001-9731-3414 


\title{
The proposal of written productions of literary genres in textbooks: stability in the face of language dynamicity
}

\begin{abstract}
Considering the importance of language practices in different linguistic materials at school and the indications of national public policies for this to occur, this article aims to discuss the proposals for literary genres in text production activities from textbooks. To do so, based on official documents, which guide the Brazilian teaching/learning practices, the article presents a reflection on discourse studies related to the work with speech genres in the school context. Finally, it analyzes the presence of the short story genre in text production activities from a high school first-year class used in private schools. The Bakhtinian studies on discourse provide the theoretical-methodological perspective of the article, from which we highlight the concepts of concrete utterance, speech genres, and activity field.
\end{abstract}

Keywords: Text production activities; Speech genres; Bakhtinian studies.

\section{Introdução}

O presente artigo tem como objetivo apresentar uma análise de uma proposta de produção escrita de gênero literário em um material de ampla circulação no Brasil, destinado à rede particular de ensino ${ }^{2}$. Tal proposta é um recorte de uma pesquisa maior, em nível de doutorado, cujo objetivo é analisar o discurso sobre a produção escrita literária de jovens em diferentes campos de atividade, especificamente, no escolar e no da arte, de modo a compreender valores sobre a produção literária escrita nesses diferentes contextos e os eventuais diálogos entre eles.

É importante destacar o fato de que o trabalho de Mikhail Bakhtin e seu grupo, para além de ser a perspectiva que norteia nosso trabalho, é muito lido no Brasil, inclusive por professores de língua materna e estudiosos da área da Linguística, desde a chegada de suas primeiras traduções em língua portuguesa, em meados da década de 90. Como resultado da produtividade dessa perspectiva teórica para os estudos da área da Linguística e da Educação, devido ao fato de ter sido lido por tais estudiosos, em um contexto de constantes mudanças e de busca por alterações nas práticas de ensino de língua portuguesa no Brasil, no entremeio do período de redemocratização do país, tivemos, em território nacional, a inclusão de conceitos dessa perspectiva teórica, a saber: língua, linguagem, texto e gêneros do discurso, nas orientações oficiais nacionais, não sem problemas, diluições ou omissões de interpretação. Destacamos, como espaços

2 Optamos pelo material do COC pelo vasto uso nacional desta coleção, com mais de 500 escolas em todo o território nacional durante mais de 50 anos de existência. 
em que está estabelecido esse diálogo - entre a teoria bakhtiniana e as orientações de ensino no Brasil - os Parâmetros Curriculares Nacionais (PCNs) (BRASIL, 1997, 1998, 2000) e suas subsequentes atualizações, durante mais de duas décadas, sendo mais recente a publicação da Base Nacional Comum Curricular (BRASIL, 2018).

Assim, no intento de discutir como são as propostas de produção escrita de gêneros do discurso, neste caso, dos literários, partimos dos documentos oficiais nacionais vigentes à época de publicação do corpus de análise, destacando a concepção de língua, de gênero do discurso e as discussões sobre práticas pedagógicas para a abordagem de textos escritos. Na sequência, destacamos conceitos para análise do enunciado em estudo da teoria de Bakhtin e do Círculo - enunciado concreto, gêneros do discurso e campo de atividade -, que, como já afırmado, são embasamento das políticas públicas nacionais e, por fim, vamos a um capítulo selecionado de um material didático, para verificar como são refratados tais conceitos e orientações. Como resultado, podemos verificar atividades de ensino-aprendizagem, mesmo com os avanços nacionais materializados nos documentos oficiais, que acompanham décadas de trabalho de estudiosos no país. Tais propostas revelam, ainda, práticas mecânicas de trabalho com a linguagem, distantes da proposta teórico-metodológica de Bakhtin. Nas seções seguintes, dedicamo-nos à exploração de tal conflituosidade.

\section{Os gêneros do discurso na perspectiva bakhtiniana e os documentos oficiais para o ensino de português no Brasil}

Os estudos bakhtinianos no Brasil são profícuos para o desenvolvimento de várias áreas da ciência nacional. Embora a recepção - descontínua em relação à organização cronológica e a versões de tradução - tenha se iniciado sobretudo pela Semiótica, nos Estudos Literários, hoje o Círculo de Bakhtin é embasamento também para estudos das áreas de Linguística e de Educação, por exemplo, em suas diferentes subáreas. Destacase, sobretudo, a recepção do texto Os gêneros do discurso (BAKHTIN, 2016), de 195253, o qual, no Brasil, gerou modificações significativas na concepção de linguagem dos estudiosos - por exemplo, a partir da proposição da perspectiva sócio-histórica para estudos da linguagem, como o sujeito - neste caso, social - no centro das relações interativas.

$\mathrm{Na}$ análise dessa temática, é importante rememorar que os estudos dos gêneros do discurso remontam à Grécia Antiga, com os postulados classificatórios de Aristóteles e de Platão. O Brasil, até meados das décadas de 80 e 90, por meio de práticas escolares de escrita que visavam à imitação dos clássicos, tinha nesses teóricos a fonte para a concepção de educação. Nesse sentido, a Língua Portuguesa era ensinada como uma "atualização" do Latim e, dessa forma, a partir das características estruturais desta última. Já o trabalho com os textos - naquele momento, com foco na leitura - era influenciado pelos modelos da Retórica e da Poética clássicas (SOARES, 2001). A produção de textos 
escritos, por sua vez, até meados do século $X X$, não era enfatizada. A prioridade era conferida ao ensino da gramática e da leitura. Tal atividade era compreendida como prática elevada, que não tinha espaço nas primeiras séries do ensino secundário, sendo reservada às últimas e sempre ligada à literatura. Naquele momento, escrever era, a partir de bons exemplos, selecionados pelo professor, produzir textos a partir de títulos pré-estabelecidos e de imagens, sob os moldes dos estudos da Retórica e da Poética. O objetivo era mesmo, praticamente, imitar os textos clássicos, dos selecionados bons autores, os que dominavam "a arte de escrever" - expressão que deu nome a muitos livros utilizados na época (BUNZEN, 2005), para, a partir disso, ter possibilidade de desenvolver sua própria prática de escrita.

Segundo Soares (2002), foi a partir dos anos 1950 que a disciplina escolar de língua portuguesa passou a ter mudanças significativas, estas associadas, sobretudo, à abertura da escola e, portanto, à recepção de uma diversidade e quantidade maior de alunos - fato que se acentuou na década de 60 e fez com que triplicasse o número de alunos matriculados, estes, agora, oriundos de diferentes classes sociais. Com essa nova característica, as exigências e condições escolares passaram a ser outras. Segundo Soares (2002, p. 167), é nesse momento que a gramática e o texto, "estudo sobre a língua e estudo da língua" passaram a ser uma disciplina única, sob a dinâmica de ora se estudar a gramática a partir do texto e ora estudar o texto com os instrumentos que a gramática fornece. Ainda que única e ainda que não separada em livros diferentes, esses dois elementos - gramática e texto - vinham organizados separadamente nos livros didáticos, assim como anteriormente, com as Antologias e as Gramáticas. Era um momento de transição no qual começavam a se delinear os novos caminhos - e pioneiros - para o trabalho com a Linguagem, na tentativa de desprendimento das sombras dos moldes clássicos. Soares (2002, p. 168) ressalta: "a gramática teve primazia sobre o texto nos anos 1950 e 1960 [...]. Esta persistente primazia da gramática talvez se explique pela força da tradição [...]. Talvez se explique também pelo vazio que o abandono da retórica e da poética deixou [...]". Nesse período, de acordo com Meserani (2002), passou-se a observar a emergência de problemas decorrentes do ensino de redação iniciado nos anos anteriores. Três foram enfatizados: "questões sobre metodologia e técnicas de ensino, sobre como ensinar; questões referentes aos modos e critérios de avaliação; questões sobre gêneros e tipos de textos, sobre o que ensinar" (MESERANI, 2002, p. 21). Segundo o autor, são essas questões que começam a fomentar os estudos teóricos e as novas propostas didáticas a partir da década de 60. Para Bunzen (2005), é nesse momento, entre anos 60 e 70, que se começa a ver um incentivo para a questão da "criatividade do aluno" no ensino de redação.

Nesse cenário de ampliação do público escolar, os livros didáticos passaram a ser modificados e a incluírem exercícios de interpretação, vocabulário, gramática e, eventualmente, de redação. Nesse momento inicia-se, também, o processo de depreciação da atividade docente, já que foi necessária a contratação de muitos professores, de maneira menos seletiva, e entendeu-se que era preciso que a atividade desse profissional 
fosse facilitada - devido à carga horária e à quantidade de alunos -, transferindo para o livro didático quase que a tarefa completa da aula (GERALDI, 2013).

Foi nos anos 70, após a instituição da Lei 5.692/71 (BRASIL, 1971), que o texto passou a ter um papel importante para além dos estudos gramaticais, enquanto ato de comunicação (BUNZEN, 2005). Segundo Soares (2002), essa foi uma mudança importante e resultado dos interesses do governo militar instaurado em 1964. Nesse cenário, a educação passou a vigorar segundo as concepções militares, a serviço do chamado desenvolvimento. Com essa visão utilitária, orientou-se que as disciplinas de Língua Portuguesa passassem a se chamar "Comunicação e Expressão", a qual dispunha de objetivos pragmáticos, visando ao bom uso da língua. De acordo com Soares (2002), foi nesse período que o estudo da gramática foi minimizado e começou-se a refletir sobre ensinar ou não gramática na escola básica. Além disso, passaram a integrar os materiais diversos tipos de gêneros para a leitura, de diferentes materialidades, e não somente os literários, nesse caminho de estudar a língua para seus usos cotidianos.

Outra questão importante na década de 70 para o ensino de língua materna é a publicação do Decreto Federal No 79.298, de 24 de fevereiro de 1977 (BRASIL, 1977), o qual, em seu artigo $1^{\circ}$, coloca como obrigatoriedade para os concursos vestibulares "prova ou questão de redação em língua portuguesa". Para Soares (1978), essa obrigatoriedade foi uma resposta aos, sobretudo, comentários da mídia que criticavam o domínio da escrita dos egressos do sistema educacional brasileiro. Em associação, a estrutura do vestibular - até então composto por questões de múltipla escolha - era criticada por muitos. As questões de múltipla escolha e a ausência da redação nos vestibulares, foram, portanto, entendidos como os causadores do fracasso dos estudantes na expressão escrita em Língua Portuguesa.

Diante desse contexto de mudança, as disciplinas de Comunicação e Expressão se sustentaram até a segunda metade da década de 80 (SOARES, 2002). Esse foi um movimento, inclusive, político, pois essas disciplinas marcavam posicionamentos políticos e ideológicos que não se sustentavam mais - estávamos no período de redemocratização. Esse período também foi importante para o desenvolvimento das ciências da linguagem, que começaram a refletir sobre o ensino de língua materna e a influenciá-lo, sobretudo a Psicolinguística, a Sociolinguística, as Análises do Discurso, a Linguística Textual, a Pragmática e a Linguística Aplicada. Nesse período, até a publicação dos Parâmetros Curriculares Nacionais (PCNs), em 1998, muitos trabalhos acadêmicos foram publicados problematizando essas questões relacionadas ao trabalho com a linguagem na escola e nos exames avaliativos vestibulares. Dentre eles, destacamos: Osakabe (1977), De Lemos (1977, 1988), Pécora (1989), Britto (1984), Geraldi (1984, 2013), Jesus (1995), Fiad e Mayrink-Sabinson (1991), Fiad (1997), Pfeiffer (1995) e Possenti (1993). 
O texto Os gêneros do discurso (BAKHTIN, 2016) chega no Brasil nesse contexto de mudança, no início da década de 90 . Esse foi um dos primeiros do autor a ser lido no Brasil e o mais citado do Círculo de Bakhtin até a atualidade. Nesse texto, o autor nos ensina que a língua se manifesta por meio de enunciados concretos (e tal adjetivo justifica-se porque são manifestações interativas reais) e únicos, no seio dos campos de atividade humana, sempre na relação entre, pelo menos, duas consciências. Nesse sentido, o estudioso russo coloca como concepção de linguagem fundamental a interação: fora dela não analisaríamos enunciados, na perspectiva do autor, mas orações, destituídas de sentido, porque o sentido só é produzido no evento discursivo, único e singular concepção distante daquela praticada até o momento.

Nesse ínterim, embora Bakhtin não despreze a generalidade em seus estudos, tendo em vista que essa é uma prática que integra o fazer científico, ele não se restringe a ela. O autor expõe o caminho para a compreensão dos enunciados, segundo sua lógica, pontuando didaticamente os modos de se compreenderem os eventos de linguagem e, nesse percurso, embora não desconsidere o repetível (da materialidade linguística), não se limita a ele:

A compreensão. Desmembramento da compreensão em atos particulares. $\mathrm{Na}$ compreensão efetiva, real e concreta, eles se fundem indissoluvelmente em um processo único de compreensão, porém cada ato particular tem uma autonomia semântica (de conteúdo) ideal e pode ser destacado do ato empírico concreto. 1) A percepção psicofisiológica do signo físico (palavra, cor, forma espacial). 2) Seu reconhecimento (como conhecido ou desconhecido). A compreensão de seu significado reprodutível (geral) na língua. 3) A compreensão de seu significado em dado contexto (mais próximo e mais distante). 4. A compreensão ativodialógica (discussão-concordância). A inserção no contexto dialógico. (BAKHTIN, 2011b, p. 398).

Assim, ainda que Bakhtin (2016, p. 12) afırme que os gêneros do discurso são enunciados formados por forma composicional, conteúdo temático e estilo, o autor é perspicaz na afirmação de que estes são "tipos relativamente estáveis de enunciados". Nesse sentido, mesmo que tenhamos elementos importantes repetíveis nessas formas de manifestação, os quais são relevantes para a efetividade da comunicação, eles são delineados a partir de elementos como a posição social do sujeito que enuncia, o campo de atividade humana do qual ele enuncia, a concepção de para quem ele se dirige, a época de produção e recepção do enunciado, a forma de circulação e recepção do discurso e as respostas que recebe (efetivamente e as previstas pelo autor). Atravessam todos esses elementos os valores ideológicos que são inerentes às organizações sociais, às épocas e aos sujeitos, aqui, singulares, porque são, na perspectiva bakhtiniana, correspondentes à pessoa individualizada e não a uma função a ser ocupada. Assim, o sujeito, para o Círculo de Bakhtin, é primordial, por ser o centro de valores que organiza o enunciado (BAKHTIN, 
2010). Sendo cada enunciado singular, composto por todos esses elementos, linguísticos e extra-linguísticos (que o penetram por dentro), os quais recebem acabamento de um sujeito sócio-histórico, são inúmeras as formas de manifestação e os gêneros do discurso, na perspectiva bakhtiniana (BAKHTIN, 2016), cada um repleto de especificidades que não podem ser desconsideradas em uma análise linguística, sob pena de minimizar o evento discursivo e reduzi-lo a formas gramaticais.

Com isso, Bakhtin foi inovador no cenário nacional ao apresentar um universo em que a linguagem não era restrita às significações das palavras, mas se mostrava heterogênea em cada acontecimento discursivo, sem hierarquização entre formas de manifestação. 0 autor colocava em cena, para os pesquisadores e professores nacionais, a necessidade de enfoque do dinâmico e do singular, no que concerne à linguagem, que retirava do palco abordagens formalistas e abstratas da linguagem, e, somado a isso, apresentava a possibilidade de análise do discurso das mais diferentes situações comunicativas da vida. Em suma, a leitura de Bakhtin por professores e pesquisadores nacionais trouxe o desafio de serem repensadas as formas de leitura e de escrita, considerando uma nova concepção de língua.

A consolidação da importância da teoria bakhtiniana para o país foi sua inclusão, por vezes, de forma indireta, nos Parâmetros Curriculares Nacionais de Língua Portuguesa $(1997,1998,2000)^{3}$, a qual alterou significativamente os estudos de língua portuguesa no Brasil ao incorporar em sua proposta a obrigatoriedade de se tomar como o centro dos estudos de língua portuguesa o texto, entendendo-o como "unidade básica da linguagem verbal" (BRASIL, 2000, p. 18), sendo o aluno, por sua vez, segundo o documento, um "produtor de textos que produz e que o constituem como ser humano" (BRASIL, 2000, p. 18), concepção esta que se afasta daquelas que são deslocadas do uso social. Deste documento, gostaríamos de destacar três pontos, os quais compreendemos como importantes avanços no trabalho com a língua portuguesa: 1) a organização da disciplina de língua portuguesa em torno de textos; 2) a proposta de diversificação de gêneros do discurso; 3) o postulado do caráter social da linguagem, sempre construído na relação (entre sujeitos, entre discursos) nos campos de atividade.

Contudo, nesses documentos, conforme já exposto por vários pesquisadores (destacase, nesse ínterim, o trabalho de Campos, 2016 e Brait, 2000), há uma diluição da teoria dos estudiosos russos. Confunde-se no texto o conceito de gêneros do discurso com o de tipos textuais, oriundo de outras teorias. Há trechos em que se descaracteriza a abordagem sócio-histórica e contextualizada dos enunciados, já que acaba sendo

3 Não é desconsiderado, neste artigo, o fato de que também outros documentos nacionais dialogam com os estudos bakhtinianos após esse período, inclusive a Base Nacional Comum Curricular, cuja última versão é de 2018. O enfoque aos PCNs justifica-se pelo contexto de publicação do corpus de análise. 
proposta uma lista de gêneros a ser estudada em cada fase da escola, cujo resultado, nas salas de aula, é o trabalho com modelos pré-estabelecidos de gêneros (com enfoque maior para a forma composicional), sob uma perspectiva estanque de abordagem da língua. Assim, o ensino passa a se delinear com o objetivo de ensinar esses gêneros, como produtos, a partir de suas características formais, distanciadas do evento singular de linguagem que se dirige sempre contextualmente a um outro.

\section{A concepção de produção literária na escola}

Os textos literários, nesse cenário de mudanças, não deixaram de estar presentes na escola e, a partir dos PCNs, passaram a ser escritos pelos alunos, supostamente, sem consistir essa prática em imitação. Nesse sentido, a partir da perspectiva bakhtiniana, ao se compreender as formas de manifestação da linguagem como singulares, assume-se que a literatura também possui uma maneira singular, específica, de orientação do enunciado na realidade (de valoração ideológica e organização da linguagem, portanto) o que a possibilita "dominar aspectos da realidade inacessíveis a outras ideologias" (MEDVIÉDEV, 2012, p. 68), não por ser superior a elas, mas diferente, dotada de acabamento estético. É isso que, por sua vez, faz com que o trabalho com a literatura necessite de metodologias que propiciem essa visão ampla do objeto estético, produzido no seio social. Segundo Medviédev, reiterando a importância da análise da língua enquanto enunciado concreto (nesse caso, estético):

Uma obra literária não pode ser compreendida fora da unidade da literatura. Mas essa unidade em seu todo, assim como cada um e seus elementos, não pode ser compreendida fora da unidade da vida ideológica. Por sua vez, essa unidade não pode ser estudada em sua totalidade, nem em seus elementos isolados, fora de uma única lei socioeconômica. Dessa forma, para extrair e determinar a fisionomia literária de uma obra, é impossível não extrair, ao mesmo tempo, sua fisionomia ideológica geral, pois uma não pode existir sem a outra, e a revelação desta última nos levará à natureza socioeconômica. Somente diante da observação de todas essas condições é possível realizar o autêntico estudo concreto da obra de arte. Não é possível escapar de nenhum dos elos dessa cadeia unitária da compreensão do fenômeno ideológico, tampouco é possível deter-se em um elo sem passar ao próximo. É completamente inadmissível estudar a obra literária direta e exclusivamente como elemento do meio ideológico, como se ela fosse um exemplar único da literatura, e não um elemento direto do mundo literário em sua peculiaridade. Sem haver concebido o lugar de uma obra na literatura e a sua dependência direta dela, não se pode compreender seu lugar no meio ideológico. (MEDVIÉDEV, 2012, p. 72).

Considerar a literatura em interação nos campos de atividade ideológica faz com que, nessa perspectiva e, segundo propõe o autor, não desconsideremos suas peculiaridades. 
Por outro lado: é somente a análise do enunciado em seu horizonte mais amplo de enunciação que permite a revelação dessas singularidades. Com isso, ressalta-se a importância dos campos de atividade, dos quais emergem os enunciados dos sujeitos. Somado a isso, deve-se ressaltar que um enunciado e, nesse caso, um texto literário, recebe acabamento sempre orientado ao outro, interlocutor e "não pode ser compreendido fora das inter-relações do falante com os ouvintes ou do autor com os leitores" (MEDVIÉDEV, 2012, p. 191), todos situados sócio-historicamente. Todas as escolhas feitas pelo autor ao elaborar o seu ato estético, as quais podem ser isoladas em uma análise abstrata de uma obra, são repletas de avaliação social, de ideologia, e somente na unidade do ato, na realidade interativa concreta, que une repetibilidade e singularidade, adquirem sentido. Nesse sentido, a abordagem da escrita literária no contexto nacional deveria ser coerente a tal posicionamento.

Os PCNs, ao não proporem explicitamente uma distinção entre gêneros do discurso, colocam os gêneros literários em relação a outros, como os jornalísticos, por exemplo. Com a mudança proposta pela Base Nacional Comum Curricular de trabalho a partir de campos de atividade, continuamos contemplando, seja em maior ou menor grau, o texto literário em sala de aula, sempre, tanto no novo documento (BNCC), quanto nos anteriores (PCNs), pontuando que o trabalho com os gêneros deve ser feito a partir da especificidade composicional, estilística, temática e de circulação de cada um deles.

Tal proposta de prática de trabalho com o texto literário em sala de aula gerou, como é de se esperar, conflito entre estudiosos da área das Letras. Essa problemática já foi destacada por Mendonça (2013), para a qual trata-se de um conflito de identidade, ampliando outros já presentes na esfera científica. A autora destaca:

O lugar que a linguagem literária ocupa nos PCN [...] aponta para um movimento de democratização dessa linguagem, integrando-a ao espaço do dizer do sujeito "comum". No entanto, por ser colocada lado a lado com os gêneros que se produzem em outras esferas (científica, de comunicação etc.), pode-se sugerir que a especificidade dos gêneros literários não deva ser considerada. (MENDONÇA, 2013, p. 12).

Contudo, assim como afirma a autora (MENDONÇA, 2013), tendo em vista que o conceito de gêneros do discurso que sustenta os PCNs é o bakhtiniano, estes não deveriam ser abordados sem suas especificidades, considerando que qualquer redução de suas características resulta em formalização e estabilização de um conceito construído, como visto, na dinamicidade. Na seção a seguir, analisamos como essa abordagem tem sido concretizada nas propostas de produção de gêneros literários em um livro didático de ampla circulação nacional. 


\section{A proposta de produção escrita de gêneros literários em um livro didático}

O material didático do Sistema de Ensino COC (BRAFF et al., s/d) tem circulação significativa no Brasil no cenário das instituições particulares de ensino. Em relação ao que nos interessa propriamente - as propostas de produção escrita de gêneros - é evidente que o material - no qual é dividida a disciplina de língua portuguesa em gramática, literatura e redação, já apontando para uma dissociação dos aspectos sóciohistóricos da concepção de linguagem - contempla essa orientação nacional de inclusão de diferentes gêneros do discurso para produção. Contudo, é voltado predominantemente a propostas de produção textual de tipo dissertativo-argumentativo, sobretudo após o $2^{\circ}$ ano do ensino médio (EM). Ao longo da coleção destinada aos três anos do EM, apenas três gêneros literários são propostos para produção do aluno: conto, crônica e biografia. Neste texto, analisamos a proposta de produção do primeiro citado.

No livro 6 do Sistema de Ensino COC, presente no material da $1^{\text {a }}$ série do Ensino Médio, temos a proposta de produção de escrita do gênero literário conto. Nesse capítulo, temse como objetivos delimitados pelo material: "1) identificar o conflito gerador do enredo e os elementos que constroem a narrativa ficcional; 2) elencar as perguntas essenciais para a construção da narrativa ficcional e estabelecer relações entre elas: 'o quê? Onde? Quando? Quem? Por quê?"' (BRAFF et al., n6, s/d, p. 72), relacionados a uma parte da constituição do gênero e não à sua totalidade enquanto enunciado concreto em atividade interativa, como propõe Bakhtin (2016a).

No capítulo, é apresentada uma breve definição do gênero conto: "o conto é uma narrativa literária pouco extensa, com economia de meios, como tempo, espaço e personagens, enfocando uma célula dramática ou conflito único. Trata-se, por essa razão, de uma narrativa geralmente curta" (BRAFF et al., $n^{\circ} 6, \mathrm{~s} / \mathrm{d}, \mathrm{p}$. 74). Note-se que, em se tratando de um gênero do discurso, tal definição, considerando a perspectiva bakhtiniana, não considera o todo do enunciado, sua forma composicional, estilo e tema (BAKHTIN, 2016a), tampouco a especificidade do enunciado em relação à esfera, nesse caso, da arte, por ser um texto literário. Ainda, não se analisa o gênero ligado ao social, à sua relação com um horizonte de enunciação, no qual ele é repleto de especificidades e função comunicativa, visando ao outro.

Na sequência, é dado início à seção "Estrutura", em que se chama atenção para a "estrutura clássica do conto", qual seja:

introdução (a descrição de espaço ou de personagem), complicação (os fatos iniciais que colocarão personagens diante de alguma situação nova), conflito (o desenvolvimento da situação, seus lances necessários), clímax (o momento de maior intensidade dramática, depois do qual é impossível prolongar o conflito) 
e epílogo (ou desfecho, a solução final do conto, com prêmio ou castigo, isto é, vitória ou derrota do protagonista. (BRAFF et al., $n^{\circ} 6, s / d, p .75$ ).

Abaixo dessa definição, é feita uma ressalva de que nem sempre essa estrutura proposta é seguida fielmente, podendo ser invertida ou ter partes suprimidas. Usa-se o advérbio "modernamente" para definir quando não se segue tais elementos. Tal consideração torna-se interessante caso fossem associadas a ela informações sobre a instabilidade dos gêneros discursivos, que possuem características próprias em cada evento discursivo, como propõe Bakhtin (2016), incorporado pelos documentos oficiais (BRASIL, 2000). Contudo, no material, essa exploração não é feita e, para ilustrar a colocação, é apresentada uma imagem de Clarice Lispector, seguida de um pequeno excerto de seu conto "Laços de Família", destacando a retirada da introdução neste.

Depois disso, como último "item" dessa seção introdutória, está a linguagem. Em relação a ela, destaca-se que deve ser "objetiva, direta, privilegiando as ações; outro pode ter a preponderância das reflexões do narrador, levando em conta muito mais os sentidos e pensamentos do que as ações" (BRAFF et al., $\left.n^{\circ} 6, s / d, p .75\right)$. Não se considera estilo (nem do gênero, nem do autor), adequação de linguagem ao contexto, ao interlocutor, ao campo, ao tipo de conto a ser escrito, à época... Mais uma vez, a estabilidade é apresentada e o aluno não é convidado à reflexão.

Seguida a essa, nova seção é apresentada, com o nome "Elementos da Narrativa do Conto". Nessa, cinco itens são apresentados, a saber: a) Narrador (no qual são destacadas as diferenças entre narrador de primeira e terceira pessoa); b) Personagens (no qual são destacadas a diferença entre protagonista, antagonista e figurante; e personagens planas ou redondas); c) Tempo (em relação ao qual apenas se afirma que a temporalidade não interfere na extensão do conto); d) Espaço (em relação ao qual se afirma que a descrição pode ser feita em detalhes ou genericamente) e e) Ação (explicado como "complexo de ações praticadas pelas personagens", as quais, segundo o material, são o que confere sentido à história). Todos esses elementos são definidos brevemente, destacando, mais uma vez, as estabilidades de cada um, e ilustrados com trechos de contos de: Guy de Maupassant e Machado de Assis. Com essa seção, finaliza-se aquilo que se entende como "abordagem teórica" do conteúdo e passa-se aos exercícios.

Os exercícios têm temáticas semelhantes, voltadas à aferição da compreensão da "estrutura clássica do conto", sem relacioná-la com o projeto de dizer de um sujeito, sem dar espaço para o diálogo do aluno com o texto e sem a dimensão desse gênero em seus campos de produção, circulação e recepção mais comuns. Ressaltamos que essa composição dos exercícios é coerente à proposta do capítulo todo, o qual, sem abordar o gênero em sua dimensão social, destaca dele apenas aspectos linguísticos, apenas àquilo relacionado à ordem do estável, distante do acontecimento discursivo do qual o aluno faz parte. 
Na sequência, ao final do capítulo, temos a proposta de produção escrita de texto do gênero conto, a qual é constituída por uma orientação breve para o aluno: "redija uma narrativa em que você seja narrador protagonista, utilizando a estrutura clássica do conto" (BRAFF et al., n 6, s/d, p. 90). Ao professor, também interlocutor, há a orientação: "oriente os alunos a utilizarem a estrutura clássica do conto e todos os elementos da narrativa" (BRAFF et al., n 6, s/d, p. 90). Se considerarmos todo o projeto de dizer do capítulo, tal proposta, embora pedagogicamente problemática, torna-se coerente quando analisada no contexto do qual faz parte.

O enunciado em questão tem como objetivo orientar os alunos, após o estudo do gênero, para a produção escrita deles. O objetivo, se relacionado aos documentos oficiais, deveria ser propiciar ao aluno uma situação em que poderia se manifestar por meio de tal gênero a fim de que, nos seus espaços de atuação na vida, pudesse interagir de maneira mais eficaz. O gênero literário, nesse caso, é abordado de maneira restrita, já que se pede uma estrutura composicional estável do enunciado, a "estrutura clássica" (conforme enunciado do gênero conto), pela qual se preza nos dois capítulos, como pudemos perceber, sem considerar a individualidade daquele que elabora e realiza o projeto de dizer, nem os estilos do gênero e suas demais especificidades, e sem destacar a relação de sentido entre forma e conteúdo. A singularidade parece ser minimizada, assim como todo o contexto de enunciação no qual os sujeitos estariam inseridos e se manifestando por meio da linguagem. Nesse sentido, há uma imagem cristalizada dos gêneros, abordada por uma descrição formal. O aluno teria, nessa perspectiva, a possibilidade de reproduzir estruturas composicionais do gênero (assim como as práticas nacionais até a década de 80 no Brasil), mas não de se constituir como autor/escritor de tal em uma situação comunicativa mais próxima à realidade externa escolar. Nesse sentido, a escolarização dessa prática de escrita transforma o gênero em forma composicional, reduzindo suas potencialidades e especificidades enquanto linguagem. Contudo, uma consideração em relação a essa questão (a imagem cristalizada dos gêneros) pode ser feita: percebe-se, no Brasil, avanços significativos propostos pela Linguística e pela Linguística Aplicada para as práticas de leitura de gêneros do discurso, incluindo os literários, em contexto escolar. Em relação às de escrita, por outro lado, ainda há um caminho a ser trilhado para que avancemos nas práticas vigentes.

A referida proposta de produção não é antecedida de textos para leitura, nem orienta o aluno para a leitura de determinados textos a fim de, a partir deles, produzir o seu, não com o intuito de imitação, mas de associar o trabalho da leitura com a escrita, de colocar o aluno em relação com mais textos para que compreenda suas características estáveis e instáveis. Além disso, não se pede para que o aluno considere seus conhecimentos e experiências próprias para a produção. Tampouco são apresentadas ao aluno as condições de produção deste texto: quem é esse sujeito que enuncia? Para quem? De qual tempo histórico e lugar social? Qual é o tipo de conto a ser trabalhado? Onde este texto circulará? Por meio de quais recursos? - ressalta-se que a preocupação com a explicitação das condições de produção dos gêneros no espaço escolar é destacada 
por estudiosos nacionais desde a década de 70 , tendo em vista os efeitos no ensino/ aprendizagem da língua quando tais considerações não são feitas, além de estar presente nos documentos oficiais que orientam o trabalho com a Língua Portuguesa. $\mathrm{Na}$ proposta em questão, também, exceto o destaque para o narrador, nenhuma especificidade em relação ao texto literário é apresentada. Isso nos mostra que temos, ainda na contemporaneidade, propostas de trabalho com os gêneros do discurso que os abordam como elementos dissociados da vida, sem destaque para suas especificidades, função social e espaços de acontecimento mais comuns. Tal proposta de trabalho afasta o aluno daquela realidade e transforma o texto em redação, porque visa à reprodução de estruturas formais para conferência por um leitor. O texto, enquanto acontecimento discursivo, nos termos bakhtinianos, e o aluno, sem álibi (BAKHTIN, 2010), também são desconsiderados nessa proposta, cujo objetivo é estritamente (re)produtor (BOURDIEU; PASSERON, 1982). O que nos parece, por meio desse enunciado, em diálogo com seu horizonte discursivo maior, é que não há uma concepção de leitura ou de trabalho com o texto que considere o sujeito, mas que, visando a uma relação mecânica de aferição de conhecimentos, não se coloca o sujeito em relação consigo e com o outro, com a cultura e com as formas de manifestação de linguagem - importante ressaltar uma possível relação entre esse fato e o de que o material em análise, de uma rede particular de ensino, possui interesses mercadológicos em sua concepção, os quais, por vezes, podem dissociar esses recursos de ensino-aprendizagem de práticas efetivas para o solo social e aproximá-los daquelas que garantam mais resultados, por exemplo, nos exames vestibulares. Assim, a abordagem do gênero conto, seguida de sua proposta de produção, retira da arquitetônica do enunciado o seu centro: o sujeito, aquele que orquestra os elementos para elucidação de um projeto de dizer visando ao outro, e a especificidade do enunciado enquanto evento discursivo. Tira-se o diálogo, princípio da linguagem, na perspectiva bakhtiniana, da constituição do enunciado.

\section{Considerações finais}

Considerando os estudos bakhtinianos, entende-se o gênero do discurso como um enunciado concreto, composto por forma composicional, conteúdo temático e estilo (BAKHTIN, 2016a). Sendo um enunciado concreto, um gênero é sempre uma manifestação situada por meio da linguagem, em que, a partir do lugar de fala de um sujeito sóciohistórico, fazem-se determinadas escolhas, tendo em vista seus interlocutores, para sua recepção e circulação na vida. Essa é uma concepção de entendimento da linguagem incorporada desde os PCNs (BRASIL, 1997, 1998, 2000) nas orientações de ensino para a área de Língua Portuguesa no Brasil, atualizadas pela BNCC (BRASIL, 2018), e que embasam - ou deveriam embasar - o trabalho com a língua em território nacional, ainda que os estudos do autor tenham sido relacionados a outros nos documentos - como da Linguística Textual -, muitas vezes, sendo dissociados de seu projeto original.

O trabalho com gêneros do discurso, quando pensado a partir do viés bakhtiniano, deve incorporar as orientações destacadas anteriormente para que o estudo do enunciado 
enquanto acontecimento possa ser efetivo na escola. Somente assumindo uma posição enquanto sujeito sócio-histórico, tendo um interlocutor determinado e ciente do espaço e tempo de produção, recepção, circulação, especificidade e função social desse enunciado é que o sujeito delineia o seu projeto de dizer, fazendo suas escolhas em relação aos três elementos que compõem o gênero, propostos por Bakhtin (2016). A ciência do gênero e não somente do tipo textual, ainda recorrente no campo escolar, é um avanço, no entanto, desconhecendo as condições de produção para o seu enunciado, o aluno devolve à escola aquilo que imagina que ela espera (GERALDI, 1984), não trabalhando, portanto, com as práticas sociais que permitam que, a partir desse trabalho, ele seja mais apto para se manifestar por meio da linguagem nos diferentes campos de atividade humana. Sem condições de produção delimitadas, o trabalho com o texto se torna redação (GERALDI, 1984), tendo em vista que o objetivo - muito claro no enunciado analisado - reduzse à aplicação de uma estrutura composicional pré-estabelecida, desconsiderando-se a relativa estabilidade do gênero (BAKHTIN, 2016) e as características do enunciado enquanto evento discursivo.

A ausência de condições de produção delimitadas acarreta, ainda, outra questão a ser problematizada: a ausência de um leitor esperado para o gênero e a não circulação dos textos produzidos em sala de aula em seus meios mais comuns. Isso significa que o texto é entendido como produto e é possivelmente esquecido após a sua produção e subsequente avaliação, já que sua produção é essencialmente parte da avaliação do aluno no país. Assim, o leitor do texto, nesse caso, o professor, torna-se, muitas vezes, avaliador e, com isso, o texto perde completamente seus laços com a vida, já que a correção visa, majoritariamente, à higienização do texto (GERALDI, 1984, 2015; JESUS, 1995) e à sua adequação aos aspectos formais do gênero - para os quais o professor é chamado atenção desde os objetivos do capítulo, até o momento da produção. A finalidade de resposta colaborativa desse outro, tendo como objetivo auxiliar esse sujeito a se comunicar de maneira mais adequada nas situações da vida, é desvalorizada em nome de uma avaliação necessária para as formalidades escolares, a qual, obviamente, faz parte do funcionamento desse campo, mas não poderia delinear todas as práticas dele para findarem em si. Nesse sentido, o aluno não é levado a refletir sobre sua produção, pensando em um leitor real. Com isso, as escolhas para o trabalho com o gênero do discurso se perdem, tendo em vista que o texto é sempre restrito ao espaço escolar e ao professor, configurando um estilo escolarizado, nos termos de Fiad (1997).

Com isso, depois de mais duas décadas da publicação dos PCNs, após o desenvolvimento da Linguística e da Linguística Aplicada no Brasil e das leituras de Bakhtin, seus comentadores e de tantos outros importantes nomes nacionais, podemos dizer que nossas práticas remontam às do século passado, mesmo às anteriores ao período da redemocratização. Os PCNs, como destacado, possuem seus problemas, contudo constituem avanço importante para a área de ensino e aprendizagem de língua portuguesa em território nacional. A BNCC continua a tentar avançar nesse cenário de práticas, restanos a espera de mais produções de materiais para que possamos analisá-los e verificar 
seus impactos. Neste momento, ficam os desafios para os membros do corpo escolar e para os pesquisadores para que sejam superadas tais abordagens conteudistas da língua, que retiram dela seu cerne: o social. Para finalizar, vale a retomada de uma reflexão de um trabalho anterior, sobre tais desafios, a fim de suscitar reflexões sobre práticas individuais, construção de materiais didáticos e elaboração de aulas na área de língua portuguesa:

[...] os [...] desafios [...] só caberiam no interior dos muros escolares se entendêssemos a instituição não somente como "casa de ensino" (com enfoque no "conteúdo"), mas também como "casa de aprendizagem", na compreensão que Ihes dá Geraldi (2010): um espaço em que haja lugar para práticas; no nosso caso, de leitura, produção de textos e análise linguística de enunciados que circulam na vida, nas interações sociais, e que, fundamentalmente, são relevantes para os alunos. (LARA; MENDONÇA, 2020, p. 207).

\section{Agradecimentos}

Esta pesquisa foi financiada pela Fundação de Amparo à Pesquisa do Estado de São Paulo (Processo 2017/25868-4). As opiniões, hipóteses e conclusões ou recomendações expressas neste material são de responsabilidade da(s) autor(as) e não necessariamente refletem a visão da FAPESP.

\section{REFERÊNCIAS}

BAKHTIN, M. M. Gêneros do discurso. In: BAKHTIN, M. M. Os gêneros do discurso. Organização, tradução, posfácio e notas de Paulo Bezerra; notas da edição russa de Serguei Botcharov. São Paulo: Editora 34, 2016. p. 11-70.

BAKHTIN, M. M. Metodologia das ciências humanas. In: BAKHTIN, M. M. Estética da criação verbal. Prefácio à edição francesa Tzvetan Todorov; introdução e tradução do russo Paulo Bezerra. 6. ed. São Paulo: Editora WMF Martins Fontes, 2011b. p. 393-410.

BAKHTIN, M. M. Para uma filosofia do ato responsável. Tradução Valdemir Miotello e Carlos Alberto Faraco. São Carlos: Pedro \& João Editores, 2010.

BOURDIEU, P.; PASSERON, J. A reprodução: elementos para uma teoria do sistema de ensino. 2. ed. Tradução Reynaldo Bairão. Rio de Janeiro: Francisco Alves, 1982.

BRAFF, M.; BRAFF, R.; CARLOS DA SILVA, B.; DEFINA, D. C.; DOS ANJOS, R. F.; RODRIGUES, C. Ensino Médio - Livro de teoria e atividades. Linguagens, códigos, ciências humanas e suas tecnologias. n. 6. Ribeirão Preto: Editora COC, s/d. 
BRAIT, B. PCNs, gêneros e ensino de língua: faces discursivas da textualidade. In: ROJO, R. (org.). A prática de linguagem em sala de aula: praticando os PCNs. São Paulo: EDUC; Campinas: Mercado das Letras, 2000. p. 15-25.

BRASIL. Parâmetros Curriculares Nacionais: primeiro e segundo ciclos do ensino fundamental. Língua portuguesa. Brasília, Secretaria de Educação Fundamental, 1997.

BRASIL. Base Nacional Comum Curricular. Versão final, 2018. Disponível em: http:// basenacionalcomum.mec.gov.br/images/BNCC_El_EF_110518_versaofinal_site.pdf. Acesso em: 26 jun. 2020.

BRASIL. CÂMARA DOS DEPUTADOS. Decreto n 79.298, de 24 de Fevereiro de 1977. Altera o Decreto no 68.908, de 13 de julho de 1971, e dá outras providências. Disponível em: https://www2.camara.leg.br/legin/fed/decret/1970-1979/decreto-79298-24-fevereiro1977-428202-publicacaooriginal-1-pe.html. Acesso em: 08 abr. 2019.

BRASIL. Parâmetros Curriculares Nacionais: Ensino Médio. Parte II. Linguagens, Códigos e suas Tecnologias. Brasília, Secretaria de Educação Fundamental, 2000.

BRASIL. Parâmetros Curriculares Nacionais: terceiro e quarto ciclos do ensino fundamental. Língua portuguesa. Brasília, Secretaria de Educação Fundamental, 1998.

BRITTO, L. P. L. Em terra de surdos-mudos. In: GERALDI, J. W. (org.). O texto na sala de aula: leitura \& produção. 2. ed. Cascavel: ASSOESTE, 1984. p. 109-119.

BUNZEN, C. Livro didático de Língua Portuguesa: um gênero do discurso. 2005. Dissertação (Mestrado em Linguística Aplicada) - Instituto de Estudos da Linguagem, Universidade Estadual de Campinas, Campinas, 2005.

CAMPOS, M. I. B. Bakhtin e o ensino de língua materna no Brasil: algumas perspectivas. Conexão Letras, v. 11, n. 16, p. 123-137, 2016.

DE LEMOS, C. T. G. Coerção e criatividade na produção do discurso escrito em contexto escolar: algumas reflexões. In: SÃO PAULO (Estado) Secretaria da Educação. Coordenadoria de Estudos e Normas Pedagógicas. Subsídios à proposta curricular de língua portuguesa para o 1. e 2. graus. São Paulo: SE/CENP, 1988. 3v.

DE LEMOS, C. T. G. de. Redações no vestibular: algumas estratégias. Cadernos de pesquisa, n. 23, dez. 1977. 
FIAD, R. O estilo escolar. In: ABAURRE, M. B. M.; FIAD, R. S.; MAYRINK-SABINSON, M.

L. T. (org.). Cenas de aquisição da escrita: o sujeito e o trabalho com o texto. Campinas: Associação de Leitura do Brasil (ALB); Mercado das Letras, 1997, p. 191-200.

FIAD, R.; MAYRINK-SABINSON, M. L. A escrita como trabalho. In: MARTINS, M. H. (org.). Questões de linguagem. São Paulo: Contexto, 1991.

GERALDI, J. W. A aula como acontecimento. In: GERALDI, J. W. A aula como acontecimento. São Carlos: Pedro e João Editores, 2015c. p. 81-112.

GERALDI, J. W. Escrita, uso da escrita e avaliação. In: GERALDI, J. W. (org.). O texto na sala de aula: leitura \& produção. 2. ed. Cascavel: ASSOESTE, 1984. p. 121-125.

GERALDI, J. W. Portos de Passagem. 5. ed. São Paulo: WMF Martins Fontes, 2013.

JESUS, C. A. de. Reescrita: para além da higienização. 1995. Dissertação (Mestrado em Linguística Aplicada) - Instituto de Estudos da Linguagem, Universidade Estadual de Campinas, Campinas, 1995.

LARA, M. T. de A.; MENDONÇA, M. C. O meme em material didático: considerações sobre ensino/aprendizagem de gêneros do discurso. Bakhtiniana, São Paulo, v. 15, n. 2, p. 185-209, abr./jun. 2020.

MEDVIÉDEV, P. N. O método formal nos estudos literários: introdução crítica a uma poética sociológica. Tradução Ekaterina Vólkova Américo e Sheila Camargo Grillo. São Paulo: Contexto, 2012.

MENDONÇA, M. C. O discurso sobre a produção textual de gêneros literários. Letras \& Letras, v. 29, n. 2, 2013.

MESERANI, S. O intertexto escolar: sobre leitura, aula e redação. São Paulo: Cortez, 2002.

OSAKABE, H. Provas de argumentação. Cadernos de Pesquisa, Campinas, UNICAMP / IEL, n. 23, 1977.

PÉCORA, A. Problemas de redação. São Paulo: Martins Fontes, 1989. 
PFEIFFER, C. R. C. Que autor é esse? 1995. Tese (Doutorado em Linguística) Universidade Estadual de Campinas, Instituto de Estudos da Linguagem, Campinas, 1995. Disponível em: http://repositorio.unicamp.br/jspui/handle/REPOSIP/270699. Acesso em: 24 nov. 2021.

POSSENTI, S. Estilo e aquisição da escrita. Estudos Linguísticos XXII - Anais de Seminários do Gel, Ribeirão Preto, v. 1, p. 202-204, 1993

SOARES, M. O livro didático como fonte para a história da leitura e da formação do professor-leitor. In: MARINHO, M. (org.). Ler e navegar: espaços e percursos da leitura. Campinas: Mercado de Letras: ALB, 2001. p. 31-76.

SOARES, M. Português na escola: História de uma disciplina curricular. In: BAGNO, M. (org.). Linguística da norma. São Paulo: Loyola, 2002. p. 155-177.

VOLOCHÍNOV, V. N. Marxismo e filosofia da linguagem. Tradução, notas e glossário de Sheila Grillo e Ekaterina Vólkova Américo. São Paulo: Editora 34, 2017.

ZILBERMAN, R. Leitura na escola - entre a democratização e o cânone. Revista Literatura em Debate, v. 11, p. 20-39, 2017. 